УДК 543.544:547.913

\title{
ИЗУЧЕНИЕ ЗАВИСИМОСТИ АНТИОКСИДАНТНОЙ АКТИВНОСТИ ЭФИРНЫХ МАСЕЛ ЛИМОНА, МАЦИСА, ФЕНХЕЛЯ И ЧЕРНОГО ПЕРЦА ОТ КОНЦЕНТРАЦИИ МАСЛА В СИСТЕМЕ МЕТОДОМ КАПИЛЛЯРНОЙ ГАЗОВОЙ ХРОМАТОГРАФИИ
}

\author{
(С) А.Л. Самусенко \\ Институт биохимической фризики им. Н.М. Эмануэля РАН, ул. Косыгина, 4, \\ Москва, 119991(Россия), e-mail: Samusenko.alexey@rambler.ru
}

\begin{abstract}
Методом капиллярной газожидкостной хроматографии исследована зависимость величины антиоксидантной активности от концентрации эфирных масел лимона (Citrus limon), мациса (Myristicia fragans L.), фенхеля (Foeniculum officinale) и черного перца (Capsicum nigrum L.) в системе. Оценка антиоксидантных свойств проведена по реакции окисления транс-2-гексеналя в соответствующую карбоновую кислоту. Найдено, что зависимость величины антиоксидантной активности масел от их концентрации непосредственно связана со скоростью изменения содержания основных веществ-антиоксидантов в составе изученных эфирных масел при длительном хранении на свету. Наиболее сильную зависимость антиоксидантной активности от концентрации наблюдали для масла лимона, а наименее сильную для масла фенхеля. Низкие концентрации масла черного перца не оказывали ингибирующего действия на окисление тест-альдегида.

Ключевые слова: пряно-ароматические растения, эфирные масла, антиоксидантная активность, капиллярная газовая хроматография.
\end{abstract}

\section{Введение}

В последнее время в результате многочисленных исследований установлена биологическая активность эфирных масел пряно-ароматических растений, в том числе антиоксидантная [1-6]. Эфирные масла пряно-ароматических растений являются альтернативой синтетическим антиоксидантам, так как использование последних часто потенциально опасно для здоровья человека [7-8]. Поэтому изучение антиоксидантной активности (AОА) эфирных масел пряно-ароматических растений является важной задачей для косметической химии, ароматерапии, пищевой и парфюмерной промышленности.

Биологическая активность эфирных масел зависит от их состава. Обнаружено, что сильными антибактериальными и АО свойствами обладают эфирные масла, содержащие замещенные фенолы - эвгенол, тимол, карвакрол и гваякол [9-14]. Относительно недавно предложены компьютерные программы, позволяющие предсказать АО активность 32 эфирных масел, используя данные о составе их активных компонентов [15].

Ранее на примере окисления альдегидов мы провели сравнительную оценку АОА эфирных масел, содержащих в своем составе монотерпены, например $\gamma$-терпинен и $\alpha$-терпинолен, или сесквитерпены (зингиберен и $\beta$-кариофиллен), которые также обладают высокой АОА [16-17]. Однако концентрация масел в системе «альдегид - эфирное масло» была достаточно высока и исследования при других значениях концентрации масла не проводили. В связи с этим было интересно изучить влияние концентрации обладаю-

Самусенко Алексей Леонидович - научный сотрудник, тел.: (499) 135-78-94, факс: (499) 137-41-01,

e-mail: Samusenko.alexey@ rambler.ru щих AOA эфирных масел на скорость окисления альдегида и сопоставить полученные результаты с количественным изменением состава активных компонентов масел. 
Цель работы - изучить зависимость АОА эфирных масел лимона, мациса, фенхеля и черного перца от их концентрации в системе и соотнести полученные данные с изменением содержания основных веществ-антиоксидантов, входящих в состав масел.

\section{Экспериментальная часть}

Исследовали свежие образцы эфирных масел: лимона («R. C. TREATT», Великобритания), мациса, фенхеля и черного перца («Plant Lipids Ltd», Индия).

Для оценки АО свойств эфирных масел и их смесей в 50 мл $н$-гексана растворили 400 мкл транс-2гексеналя и 400 мкл н-додекана (8 мкл/мл); последний служил внутренним стандартом. Раствор разделили на аликвоты по 2 мл, которые поместили в стеклянные пробирки объемом 10 мл, и добавили по 200, 100, 50 или 20 мкл эфирных масел лимона, мациса, фенхеля и черного перца (всего 16 образцов). В контрольный образец масло не добавляли. Каждый образец был приготовлен двукратно. Образцы в закрытых пробками пробирках держали на свету при комнатной температуре в течение 145 сут. Источником света служило естественное освещение в лаборатории. Каждую неделю пробирки открывали и продували 10 мл воздуха с помощью пипетки. Количественное содержание гексеналя в пробирках определяли методом капиллярной газовой хроматографии через каждые 8-12 сут в первые 3 мес. хранения, а затем с интервалом в 1 мес. Изменения в составе эфирных масел фиксировали через 1, 2, 3, 4 и 5 мес. с начала хранения.

Газохроматографический анализ образцов эфирных масел проводили на хроматографе Micromat-412 фирмы Nordion Instr. (Финляндия) на кварцевой капиллярной колонке SPB-1 (Supelco, CША, 35 м × 0,32 мм, толщина слоя фазы 0,25 мкм) при программировании температуры колонки от 60 до $250{ }^{\circ} \mathrm{C}$ со скоростью 8\%мин. Скорость газа-носителя - гелия составляла 1 мл/мин, температура инжектора и пламенноионизационного детектора $-250{ }^{\circ} \mathrm{C}$. Идентификацию компонентов в образцах масел осуществляли на основе величин индексов удерживания путем их сопоставления с литературными [18] или экспериментальными данными, полученными нами. Количественное содержание гексеналя и компонентов эфирных масел рассчитывали по отношению площадей пиков, соответствующих веществам и внутреннему стандарту, содержание которого принимали кратным 8 мкл/мл. Степень окисления гексеналя и компонентов эфирных масел (отн.\%) определяли по отношению к их содержанию в исходных образцах.

\section{Результаты и обсуждение}

Для оценки антиоксидантной активности (AОА) исследуемых эфирных масел мы использовали тест «альдегид/карбоновая кислота» [19]. Этот метод успешно применяли для проверки АО активности летучих экстрактов из различных растений, например гвоздики и эвкалипта [20] и некоторых сортов зеленого и черного чая [21].

В качестве альдегида нами выбран транс-2-гексеналь, который окислялся до 2-гексеновой кислоты; в качестве критерия оценки АО активности - «период полуокисления» (ПО) альдегида, т.е. время, в течение которого окислялась половина исходного количества альдегида. Как видно из рисунка 1, все исследованные масла обладали различной АО активностью. В контрольном растворе (К) ПО альдегида составлял 21 сут, в то время, как наличие в растворе эфирных масел в той или иной степени ингибировало окисление альдегида.

При уменьшении концентрации масла с 10 до 5, 2.5 и 1 об.\% мы отмечали последовательное снижение АОА системы «альдегид - эфирное масло». Особенно резкое снижение АОА наблюдали на примере масла лимона (рис. 2). В то время как при концентрации масла $10 \%$ ПО гексеналя составлял 132 сут, в $1 \%$-м масле эта величина не превышала 30 сут., тем самым практически приближаясь к величине ПО альдегида в контрольном растворе. Иную картину наблюдали в случае масла мациса, где аналогичные величины ПО составляли 103 и 50 сут (рис. 2), то есть снижение АОА в том же диапазоне концентраций масла происходило менее резко. 


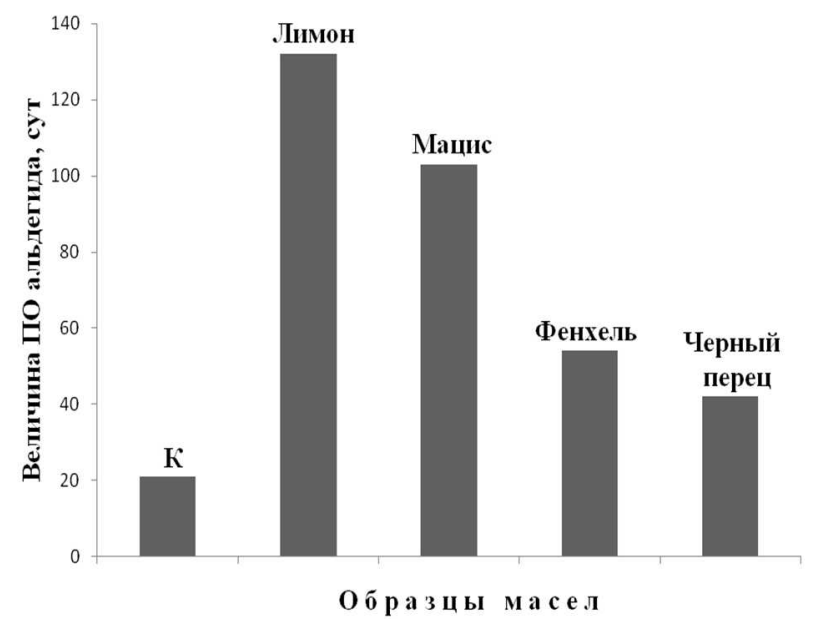

Рис. 1. Период полуокисления (ПО) транс-2-гексеналя в различных эфирных маслах: К - контроль, концентрации всех масел 10 об.\%.

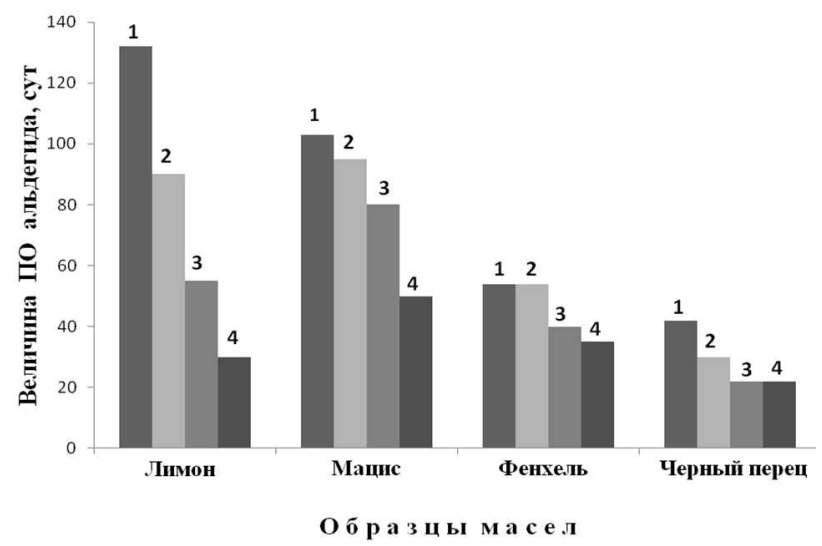

Рис. 2. Зависимость величины ПО транс-2-гексеналя от концентрации эфирного масла в системе: концентрации масел: $1-10 \%$; $2-5 \% ; 3-2,5 \% ; 4-1 \%$

Поскольку и лимонное и масло мациса содержат сильный антиоксидант - $\gamma$-терпинен, мы проследили изменение его содержания в системе в процессе окисления. Известно, что $\gamma$-терпинен легко окисляется до $n$-цимена по реакции:

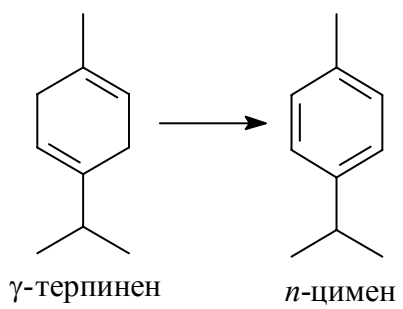

предотвращая тем самым окисление тест-альдегида. Изменение содержания $\gamma$-терпинена в маслах лимона и мациса представлено на рисунках 3 и 4. Как видно из рисунка 3, в 1\%-м масле лимона $\gamma$-терпинен практически полностью окислялся за 30 сут, в то время как в 10\%-м масле его содержание оставалось значительным даже спустя 60 сут процесса. В случае масла мациса (рис. 4) окисление $\gamma$-терпинена происходило с меньшей скоростью, а именно - в 10\%-м масле его содержание оставалось высоким (более 50\%) даже после 110 сут окисления. При снижении концентрации масла до 1\% после 30 сут сохранялось около 20\% неокисленного вещества.

Согласно результатам проведенного нами газохроматографического анализа изучаемых масел, содержание $\gamma$-терпинена в мацисе примерно в 2 раза меньше, чем в лимоне, а именно - 5,6\%, в то время как в лимонном масле - 12,1\%. Тем не менее скорость окисления $\gamma$-терпинена в мацисе, как видно из данных рисунков 3 и 4, значительно меньше, чем в лимоне. Это можно объяснить наличием в составе эфирного масла мациса более высоких концентраций других монотерпеновых углевородоров, которые, как отмечено в [22], также являются антиоксидантами. Вероятно, поэтому, несмотря на меньшие значения величин ПО альдегида в масле мациса по сравнению с маслом лимона, зависимость АОА от концентрации масла в случае мациса менее резко выражена.

Наименее выраженную зависимость величины АОА от концентрации масла в системе наблюдали для эфирного масла фенхеля (см. рис. 2). Масло фенхеля, как видно из рисунка 1, обладало средней активностью среди четырех изученных масел. Такой сильный антиоксидант, как $\gamma$-терпинен, в его составе отсутствует; по-видимому, основным веществом-антиоксидантом в этом случае являлся транс-анетол. Рисунок 5 демонстрирует скорость изменения его содержания в растворе в зависимости от концентрации масла в системе. Как видно из рисунка 5, при снижении концентрации масла с 10 до 5\% скорость изменения анетола в растворе практически не изменялась. Это находится в соответствии с величиной ПО альдегида, которая составляла 54 сут для обеих концентраций масла фенхеля. При дальнейшем снижении концентрации масла наблюдали более выраженную зависимость изменения содержания анетола от концентрации, соответственно уменьшалась и его АОА (см. рис. 2). 
Масло черного перца обладало самой низкой АОА среди изученных эфирных масел (см. рис. 1). Если при 10\%-й его концентрации ПО альдегида в масле превышал в 2 раза величину ПО в контрольном растворе, то уже при концентрации 2,5\% мы не наблюдали АОА масла (ср. рис. 1 и 2). Основной компонентантиоксидант в масле черного перца - $\beta$-кариофиллен при хранении на свету быстро окислялся до кариофиллен-оксида:<smiles>C=C1CCC(C)=C(C)CC[C@H]1C</smiles>

$\beta$-кариофиллен<smiles>C=C1CCC2OC2(C)CCC2C1CC2(C)C</smiles>

кариофиллен-оксид

Следовательно, его содержание резко снижалось для всех концентраций масла (рис. 6). Поэтому низкие концентрации масла черного перца не проявили АОА по отношению к гексеналю.

Таким образом, проведенное исследование показало, что величина АОА изученных эфирных масел находится в зависимости от их концентрации в системе, причем эта зависимость индивидуальна для каждого масла. АОА всех масел снижается при уменьшении концентрации масла, и скорость этого снижения связана с изменением содержания активных компонентов в составе масла в процессе автоокисления. Знания о характере зависимости АОА того или иного масла от его концентрации позволяют целенаправленно регулировать стабильность систем, в которые эфирные масла входят в качестве ингредиентов.

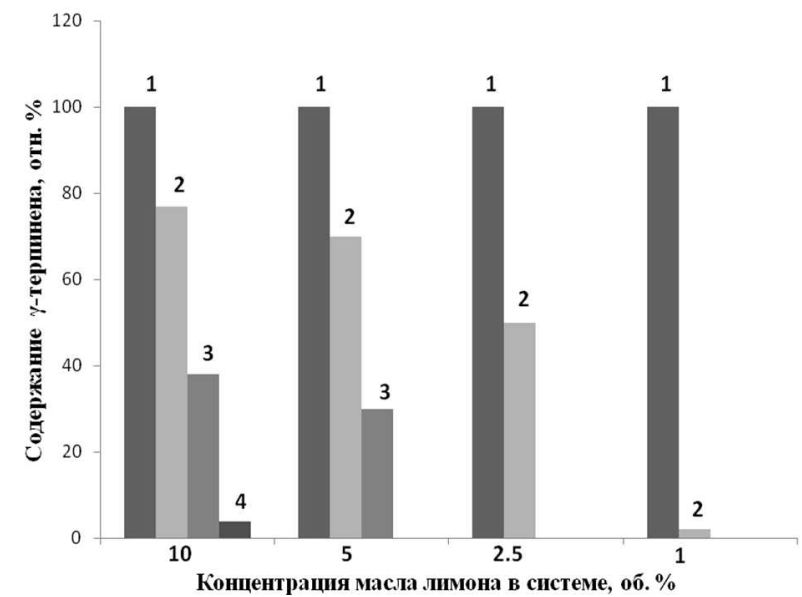

Рис. 3. Лимон - $\gamma$-терпинен

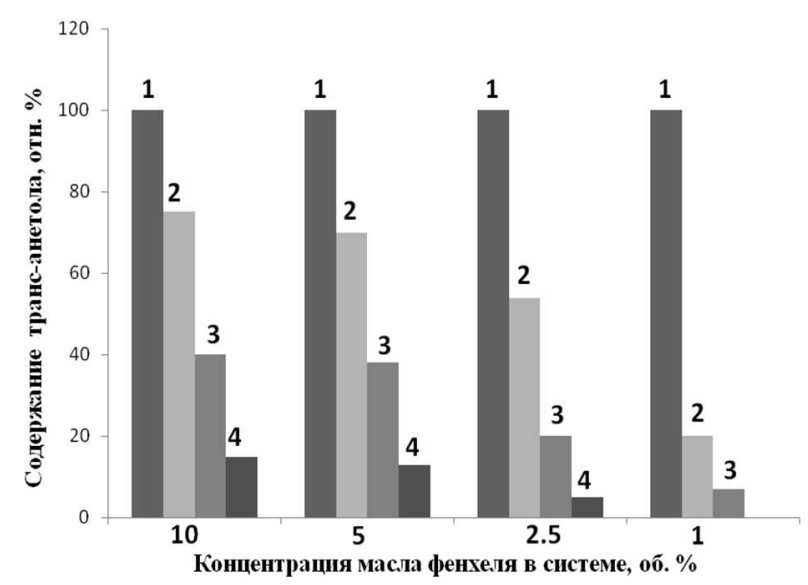

Рис. 5. Фенхель - транс-анетол

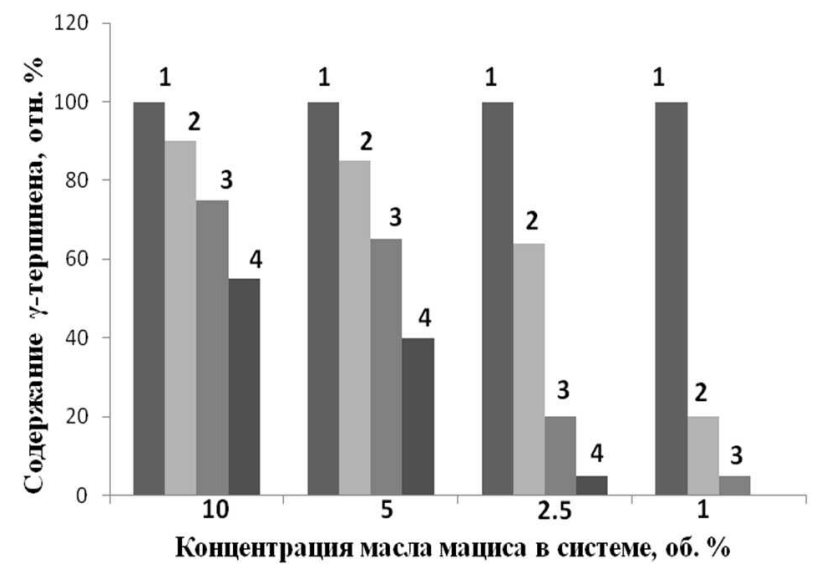

Рис. 4. Мацис - $\gamma$-терпинен

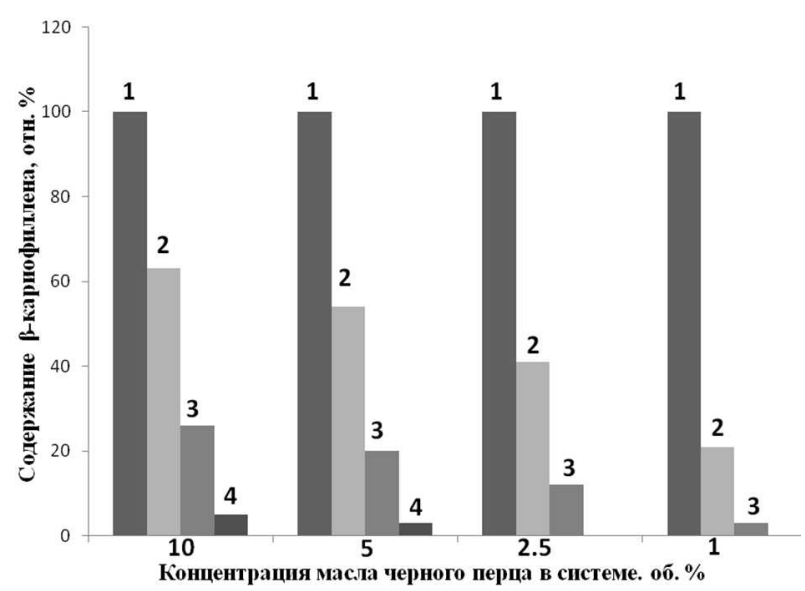

Рис. 6. Черный перец - $\beta$-кариофиллен

Изменение содержания веществ-антиоксидантов при различных концентрациях эфирных масел в процессе окисления; обозначения: 1 - 0; 2 - 30; 3 - 60; 4 - 110 сут процесса 


\section{Выводы}

Методом капиллярной газовой хроматографии обнаружено, что зависимость величины антиоксидантной активности эфирных масел от их концентрации непосредственно связана со скоростью изменения содержания основных веществ-антиоксидантов в составе изученных масел при длительном хранении на свету.

Наиболее резкую зависимость антиоксидантной активности от концентрации наблюдали для масла лимона, а наименее - для масла фенхеля.

Низкие (менее 5 об.\%) концентрации масла черного перца не оказывали ингибирующего действия на окисление тест-альдегида.

\section{Список литературы}

1. Burt S. Essential oils: their antibacterial properties and potential applications in foods // Int. J. Food Microbiol. 2004. Vol. 94, N3. Pp. 223-253.

2. Hsu F.-L., Li W.-H., Yu C.-W., Hsieh Y.-C., Yang Y.-F., Liu J.-T., Shih J., Chu Y.-J., Yen P.-L., Chang S.-T., Liao V.H.-C. In vivo antioxidant activities of essential oils and their constituents from leaves of the taiwanese Cinnamomum Osmophloeum // J. Agric. Food Chem., 2012. Vol. 60, N12. Pp. 3092-3097.

3. Özcan M.M., Arslan D. Antioxidant effect of essential oils of rosemary, clove and cinnamon on hazelnut and poppy oils // Food Chem. 2011. Vol. 129, N1. Pp. 171-174.

4. Wei A., Shibamoto T. Antioxidant/Lipoxygenase Inhibitory Activities and Chemical Compositions of Selected Essential Oils // J. Agric. Food Chem., 2010. Vol. 58, N12. Pp. 7218-7225.

5. El-Ghorab H., Nauman M., Anjum F.M., Hussain S. And Nadeem M. A Comparative Study on Chemical Composition and Antioxidant Activity of Ginger (Zingiber officinale) and Cumin (Cuminum cyminum) // J. Agric. Food Chem. 2010. Vol. 58, N14. Pp. 8231-8237.

6. Ferreira F.D., Kemmelmeier C., Arrotéia C.C., da Costa C.L., Mallmann C.A., Janeiro V., Ferreira F.M.D., Mossini S.A.G., Silva E.L., Machinski M. Jr. Inhibitory effect of the essential oil of Curcuma longa L. And curcumin on aflatoxin production by Aspergillus flavus Link // Food Chem. 2013. Vol. 136, N2. Pp. 789-793.

7. Schilderman P., ten Vaarwerk F.J., Lutgerink J.T., Van der Wurff A., ten Hoor F., Kleinjans J.C. Induction of oxidative DNA damage and early lesions in rat gastro-intestinal epithelium in relation to prostaglandin $\mathrm{H}$ synthasemediated metabolism of butylated hydroxyanisole // Food Chem. Toxicol. 1995. Vol. 33. Pp. 99-109.

8. Witschi H., Morse C. Enhanced lung tumor formation in mice by dietary BHT // J. Natl. Cancer Inst. 1983. Vol. 71. Pp. 859-866.

9. Lee K.-G., Shibamoto T. Determination of antioxidant potential of volatile extracts isolated from various herbs and spices // J. Agric. Food Chem. 2002. Vol. 50, N17. Pp. 4947-4952.

10. Dorman H.J.D., Figueiredo A. C., Barroso J. G., Deans S.G. In vitro evaluation of antioxidant activity of essential oils and their components // Flavour Fragr. J. 2000. Vol. 15. Pp. 12-16.

11. Lee K.-G., Shibamoto T. Antioxidant properties of aroma extract isolated from clove buds [Syzygium aromaticum (L.) Merr. Et Perry] // Food Chem. 2001, Vol. 74, N4. Pp. 443-448.

12. Kahkonen M.P., Hopia A.I., Vuorela H. J., Rauha J.-P., Pihlaja K., Kujala T. S., Heinonen M. Antioxidant Activity of Plant Extracts Containing Phenolic Compounds // J. Agric. Food Chem. 1999. Vol. 47, N10. Pp. 3954-3962.

13. Areias F., Valentao P., Andrade P.B., Ferreres F., Seabra R.M. Flavonoids and Phenolic Acids of Sage: Influence of Some Agricultural Factors // J. Agric. Food Chem. 2000. Vol. 48, N12. Pp. 6081-6084.

14. Ruberto G., Baratta M.T. Antioxidant activity of selected essential oil components in two lipid model systems // Food Chem. 2000. Vol. 69, N2. Pp. 167-174.

15. Cabrera A.C., Prieto J.M. Application of artificial neural network to the prediction of the antioxidant activity of essential oils in two experimental in vitro models // Food Chem. 2010. Vol. 118, N1. Pp. 141-146.

16. Самусенко А.Л. Сравнительная оценка антиоксидантной активности эфирных масел пряно-ароматических растений методом капиллярной газовой хроматографии // Химия растительного сырья. 2010. №3. С. 107-113.

17. Самусенко А.Л. Исследование антиоксидантной активности эфирных масел лимона, розового грейпфрута, кориандра, гвоздики и их смесей методом капиллярной газовой хроматографии // Химия растительного сырья. 2011. №3. С. 107-112.

18. Jennings W., Shibamoto T. Qualitative Analysis of Flavor and Fragrance Volatiles by Glass Capillary Gas Chromatography. New York; London; Sydney; Toronto; San Francisco, 1980. 472 p.

19. Lee K.G., Shibamoto T. Determination of antioxidant potential of volatile extracts isolated from various herbs and species // J. Agric. Food Chem. 2002. Vol. 50, N17. Pp. 4947-4952.

20. Lee K.G., Shibamoto T. Inhibition of malonaldehyde formation from blood plasma oxidadation by aroma extracts and aroma components isolated from clove and eucalyptus // Food and Chem. Toxicol. 2001. Vol. 39, N12. Pp. 1199-1204.

21. Yanagimoto K., Ochi H., Lee K.G., Shibamoto T. Antioxidative activities of volatile extracts from green tea, oolong tea, and black tea // J. Agric. Food Chem. 2003. Vol. 51, N25. Pp. 7396-7401.

22. Sacchetti G., Maietti S., Muzzoli M., Scaglianti M., Manfredini S., Radice M., Bruni R. Comparative evaluation of 11 essential oils of different origin as functional antioxidants, antiradicals and antimicrobials in foods // Food Chem. 2005. Vol. 91, N4. Pp. 621-632. 
Samusenko A.L. INVESTIGATION OF DEPENDENCE OF ANTIOXIDANT ACTIVITY OF ESSENTIAL OILS FROM LEMON, MACE, FENNEL AND BLACK PEPPER ON OIL CONCENTRATION BY CAPILLARY GAS-LIQUID CHROMATOGRAPHY

Institute of Biochemical Physics of N.M. Emanuel Russian Academy of Sciences, Kosygina st., 4, Moscow, 119991

(Russia), e-mail: Samusenko.alexey@rambler.ru

In recent time the biological activity of essential oils from spicy-aromatic herbs, including the antioxidant one, have been evaluated in numerous studies. Earlier we have demonstrated the high antioxidant activity of the oils contained monoterpenes, such as $\gamma$-terpinene and $\alpha$-terpinolene, or sesquiterpenes (zingeberene and $\beta$-caryofillene). However the concentration value of oils in the «aldehyde - essential oil» system was too high and the investigation of various concentrations was not carried out by us. The goal of this work was studying of the influence of oil concentration on antioxidant activity value for selected essential oils. The antioxidant properties of the essential oils from lemon (Citrus limon), mace (Myristicia fragans L.), fennel (Foeniculum officinale) and black pepper (Capsicum nigrum L.) have been studied in a wide interval of oil concentrations by capillary gas-liquid chromatography, using an aldehyde/carboxylic acid assay. Trans-2-hexenal was selected to serve as the test substance. The dependence of oil antioxidant activity on its concentration was found to be closely connected with a rate of content change of main antioxidants in the composition of the essential oils under study at prolonged exposure to light. It was observed the strongest dependence «antioxidant activity - oil concentration» for lemon oil, while fennel oil possessed the weakest one. The low concentrations of oil from black pepper did not inhibit the aldehyde oxidation.

Keywords: spicy-aromatic herbs, essential oils, antioxidant activity, capillary gas chromatography.

\section{References}

1. Burt S. Int. J. Food Microbiol., 2004, vol. 94, no. 3, pp. 223-253.

2. Hsu F.-L., Li W.-H., Yu C.-W., Hsieh Y.-C., Yang Y.-F., Liu J.-T., Shih J., Chu Y.-J., Yen P.-L., Chang S.-T., Liao V.H.-C. J. Agric. Food Chem., 2012, vol. 60, no. 12, pp. 3092-3097.

3. Özcan M.M., Arslan D. Food Chem., 2011, vol. 129, no. 1, pp. 171-174.

4. Wei A., Shibamoto T. J. Agric. Food Chem., 2010, vol. 58, no. 12, pp. 7218-7225.

5. El-Ghorab H., Nauman M., Anjum F.M., Hussain S., Nadeem M. J. Agric. Food Chem., 2010, vol. 58, no. 14, pp. 8231-8237.

6. Ferreira F.D., Kemmelmeier C., Arrotéia C.C., da Costa C.L., Mallmann C.A., Janeiro V., Ferreira F.M.D., Mossini S.A.G., Silva E.L., Machinski M.Jr. Food Chem., 2013, vol. 136, no. 2, pp. 789-793.

7. Schilderman P., ten Vaarwerk F.J., Lutgerink J.T., Van der Wurff A., ten Hoor F., Kleinjans J.C. Food Chem. Toxicol., 1995, vol. 33, pp. 99-109.

8. Witschi H., Morse C. J. Natl. Cancer Inst., 1983, vol. 71, pp. 859-866.

9. Lee K.-G., Shibamoto T. J. Agric. Food Chem., 2002, vol. 50, no. 17, pp. 4947-4952.

10. Dorman H.J.D., Figueiredo A. C., Barroso J. G., Deans S.G. Flavour Fragr. J., 2000, vol. 15, pp. 12-16.

11. Lee K.-G., Shibamoto T. Food Chem., 2001, vol. 74, no. 4, pp. 443-448.

12. Kahkonen M.P., Hopia A.I., Vuorela H. J., Rauha J.-P., Pihlaja K., Kujala T.S., Heinonen M. J. Agric. Food Chem., 1999, vol. 47, no. 10, pp. 3954-3962.

13. Areias F., Valentao P., Andrade P.B., Ferreres F., Seabra R.M. J. Agric. Food Chem., 2000, vol. 48, no. 12, pp. 6081-6084.

14. Ruberto G., Baratta M.T. Food Chem., 2000, vol. 69, no. 2, pp. 167-174.

15. Cabrera A.C., Prieto J.M. Food Chem., 2010, vol. 118, no. 1, pp. 141-146.

16. Samusenko A.L. Khimiia rastitel'nogo syr'ia, 2010, no. 3, pp. 107-113. (in Russ.).

17. Samusenko A.L. Khimiia rastitel'nogo syria, 2011, no. 3, pp. 107-112. (in Russ.).

18. Jennings W., Shibamoto T. Qualitative Analysis of Flavor and Fragrance Volatiles by Glass Capillary Gas Chromatography. New York; London; Sydney; Toronto; San Francisco, 1980. 472 p.

19. Lee K.G., Shibamoto T. J. Agric. Food Chem., 2002, vol. 50, no. 17, pp. 4947-4952.

20. Lee K.G., Shibamoto T. Food and Chem. Toxicol., 2001, vol. 39, no. 12, pp. 1199-1204.

21. Yanagimoto K., Ochi H., Lee K.G., Shibamoto T. J. Agric. Food Chem., 2003, vol. 51, no. 25, pp. 7396-7401.

22. Sacchetti G., Maietti S., Muzzoli M., Scaglianti M., Manfredini S., Radice M., Bruni R. Food Chem., 2005, vol. 91, no. 4, pp. 621-632. 